Copyright Philosophy of Science 2017

Preprint (not copyedited or formatted)

Please use DOI when citing or quoting

\title{
Title: Against Organizational Functions
}

\section{Author: Justin Garson}

Abstract: Over the last 20 years, several philosophers developed a new approach to biological functions, the organizational (or systems-theoretic) approach. This is not a single theory but a family of theories based on the idea that a trait token can acquire a function by virtue of the way it contributes to a complex, organized, system, and thereby to its own continued persistence, as a token. I argue that the organizational approach faces a serious liberality objection. I examine three different ways organizational theorists have tried to avoid that objection and show how they fail.

Keywords: Philosophy of biology; biological function; organizational functions; systems theory; selected effects

Address: Department of Philosophy, Hunter College of the City University of New York, 695 Park Ave., New York, NY 10065.

Email: jgarson@hunter.cuny.edu

Acknowledgements: I am very grateful to Matteo Mossio and Gerhard Schlosser for comments on an earlier version of this argument. I am also grateful to the audience members at PSA 2016 for their insightful criticisms and suggestions. 
Copyright Philosophy of Science 2017

Preprint (not copyedited or formatted)

Please use DOI when citing or quoting

\section{Introduction.}

What are biological functions? How do we know what something's function is? What are dysfunctions? These questions drive the biological functions debate. Philosophers of science have puzzled over functions for over sixty years, ever since figures like Ernest Nagel and Carl Hempel proposed intricate, though opposing, theories about what functions are (Nagel 1953; Hempel 1965). New theories of function continue to abound. About 20 years ago, there were three main theories of biological function on the market: the selected effects theory, the fitness-contribution theory, and the causal role theory. Since then, several new theories have emerged that do not fit naturally into that canonical framework, including the modal theory (Nanay 2010), the generalized selected effects theory (Garson 2011; 2012; 2015; forthcoming) and the organizational theory (see Garson 2016 for a recent overview).

Here, I argue that we should reject the organizational theory of function. My argument is simple: I first examine the basic organizational account, and show that it succumbs to a well-known liberality problem. Then I examine three different attempts organizational theorists have made to solve the problem, and I'll show how they either succumb to comparable liberality problems, or they fail to be naturalistic. Although I sketched this basic liberality objection in another place (Garson 2016, Chapter 6), here, I go beyond that presentation by developing the objection in more detail and considering, and rejecting, two new objections to my argument.

\section{The Liberality Objection.}

What is the organizational theory? There are different versions but they all share a unifying idea: a trait token can acquire a function by virtue of the way it contributes to a complex, organized, system, and thereby to its own persistence, as a token. Consider the heart. The heart beats. In beating, it circulates blood. In circulating blood, it carries nutrients to the cells and eliminates wastes. In doing this, it helps to repair and rebuild the cells of the body, including the cells that make up the heart. So, the heart contributes to its own persistence in the organism. It does so by making a contribution to a complex, organized system (in this case, the circulatory system). Organizational theorists think this process is sufficient, with some qualifications, for creating new functions.

Contributions to self-persistence, however, are not necessary for creating new functions. Some trait tokens, like bee stingers, have functions but do not contribute to their own persistence as tokens. Rather, they acquire new functions because they contribute to the multiplication of their kind. As a consequence, it seems to me that the best way to frame the organizational theory is as a disjunctive theory, as Schlosser (1998) implicitly does and Delancey (2006) explicitly does. I will dub this the "basic" organizational theory. The basic organizational theory holds, roughly, that trait $T$ has function $F$ either because $T$ 's doing $F$ contributes to the intragenerational persistence of $T$, or, $T$ 's doing $F$ contributes to the intergenerational multiplication of $T$. Some authors prefer not to frame the theory in this disjunctive manner. Saborido et al. (2011, 600), for example, 
Copyright Philosophy of Science 2017

Preprint (not copyedited or formatted)

Please use DOI when citing or quoting

recommend a unified account of functions, where all functions involve contributions to "self-maintaining systems." In the case of the heart, the self-maintaining system is the individual; in the case of the bee-stinger, the self-maintaining system includes a lineage of organisms (see Artiga and Martínez 2016 for criticism of this move; see Mossio and Saborido 2016 for a response).

Once we have the basic framework in place, it is easy to see how to create new versions of the theory by modifying the temporal parameter. For example, one could hold that the relevant contributions to persistence must have occurred in the past. This would give us a backwards-looking version of the theory. McLaughlin (2001) endorses this approach. One could, alternatively, maintain that a trait can acquire a new function by virtue of how it currently contributes to its own future persistence (or the way it raises the probability of its own persistence). This gives us a forward-looking theory, and is clearly the intent of Schlosser (1998), Christensen and Bickhard (2002), Sarkar (2005, 18) and Weber (2005). A third approach is atemporal. One could say that part of a system has a function because of the way the system, as a whole, instantiates a certain abstract pattern of functional dependencies. This is the stance adopted by Mossio and Saborido (2016). The problem I raise below affects all versions equally.

On the face of it, all of these versions of the organizational approach face a serious challenge, namely, the Boorse-type liberality objection. This problem actually traces back to Larry Wright's $(1973,161)$ early version of the etiological theory. In Wright's view, roughly, the function of $T$ is $F$ if and only if $T$ is there because $T$ results in $F$. Wright's view was liberal enough to include both the case where $T$ contributed to its own intragenerational persistence, and the case where $T$ contributed to its intergenerational multiplication. After all, it is true to say that my heart (that is, that particular token) is there - that is, that it exists now - because it causes blood circulation. If it did not (recently) cause blood circulation then I would have died and my heart would no longer exist. So, Wright's view can be read as a precursor to the organizational view.

Boorse (1976), however, developed a devastating argument against Wright's view. He came up with a series of clever counterexamples to show that the view, as stated, was too liberal. Suppose that a hose in a laboratory springs a leak and emits a noxious chemical, and any scientist that attempts to seal it gets knocked unconscious by the chemical it emits (72). The leak is there because it knocks out scientists. But that is not its function. Similar counterexamples abound. Obesity contributes to a sedentary lifestyle, which reinforces obesity. So one can explain a person's current obesity in terms of the past consequences of his or her obesity (Ibid., 75-6). Yet obesity does not have the function of contributing to a sedentary lifestyle.

One way to exclude all of these counterexamples is by defining "function" in terms of natural selection (or comparable selection processes). This is the conclusion that both Karen Neander (1983) and Ruth Millikan (1984) independently arrived at. This move avoids the Boorse-type counterexamples. After all, obesity was not selected for contributing to a sedentary lifestyle, so it does not have this as a function (Neander 1983, 
Copyright Philosophy of Science 2017

Preprint (not copyedited or formatted)

Please use DOI when citing or quoting

103). Organizational theorists reject this route. They think they can preserve the core insight of Wright's theory, but add some extra conditions to exclude those problematic cases. So I call it a "persistence-plus" theory. Schlosser (1998) tries to avoid the Boorsetype counterexamples by introducing a complexity criterion. Mossio et al. (2009) try to avoid the liberality problem by invoking the idea of organizational differentiation. McLaughlin adds a normative, value element. I will show how each move fails.

\section{Complexity.}

Schlosser (1998) is the first paper to work out the organizational approach in detail. He refers to it as the "systems-theoretical" view of functions. He eschews the backwardslooking approach in favor of a forward-looking approach. In his view, a trait $T$ has function $F$ just in case $T$ 's doing $F$ contributes either to the intergenerational reproduction of $T$, or, the intragenerational persistence of $T$ (this is a substantially condensed paraphrase of his definition on page 315). He coins a neologism for this disjunction: "self-re-production." A system is a self-re-producing one if it undergoes a series of state transitions that ensures the recurrence of certain states $(311)$. Weber $(2005,39)$ endorses a similar view. Sarkar $(2005,18)$ writes that the "broad sense" function of a trait consists in its contribution to the persistence of the system of which it is a part, but he does not insist that the trait must thereby contribute to its own persistence.

Schlosser realizes that his theory, as stated, is vulnerable to the Boorse-type counterexamples. As he notes, if something could acquire a function just by contributing to its own self-re-production, then we could say that the function of the leaky hose is to knock out scientists (311). What additional criterion, then, must we add to exclude such systems? Schlosser says that states of a self-re-producing system can have functions only if the system has the right sort of complexity. By "complexity," he means that the state in question can utilize diverse means, or mechanisms, to bring about its self-re-production. A complex self-re-producing system "does not [merely] pass through simple cycles of states, but instead can re-produce a certain state via different sequences of state transitions depending on the environmental conditions (312)." Consider the extremely diverse behaviors that the mimic octopus (Thaumoctopus mimicus) uses to camouflage itself. It can mimic several different kinds of living creatures, including flatfish, lionfish, and sea snakes, depending on the circumstances. The neural mechanism underlying its mimicry can perform several different sorts of activities in different circumstances to ensure its continued existence, so it has a function. In contrast, a leaky hose can only do one thing to contribute to its own persistence, namely, spew gas. So it does not have a function.

One might question this view on the grounds that it excludes things that, by right, deserve functions. For example, protective coloration in moths and butterflies does not seem to achieve its function in a very complex way. By making the moth resemble its surroundings, coloration makes the moth hard to see. That is not significantly more complex than the leaky hose. Here, I believe Schlosser would say that, by virtue of helping the moth avoid getting eaten, the protective coloration lets the moth do many 
Copyright Philosophy of Science 2017

Preprint (not copyedited or formatted)

Please use DOI when citing or quoting

other things, like find food and mates. So there are a potentially vast number of causal pathways that explain how the trait persists over time or reproduces its kind.

However, Schlosser's account does not exclude all of the counterexamples it should. A well-documented psychiatric example of a complex self-reproducing system is panic disorder (APA 2013, 208). Panic disorder is characterized by recurring panic attacks, which are sudden but intense episodes of fear or discomfort. Interestingly, there are a number of ways in which panic disorder, that is, the disposition to have panic attacks, perpetuates itself over time, as I will shortly explain. But the parts of panic disorder do not have functions.

The cognitive behavioral therapist (CBT) David Clark (1986) established the core theory of panic disorder in the 1980s, and much of the current research in CBT builds on this foundation. In Clark's view, single panic attacks result from "catastrophizing" misinterpretations of bodily sensations. One experiences an unusual bodily sensation, such as mild lightheadedness from a yoga posture. One then misinterprets the sensation as a sign of impending catastrophe (such as a heart attack) and becomes very apprehensive and vigilant to new sensations. This sets up a simple feedback loop that culminates in a panic attack.

What is more interesting for my purpose is the way that panic attacks tend to set the stage for their own recurrence. Cognitive behavioral therapists have identified diverse mechanisms, or means, by which this happens (Clark 1997, 125). First, someone who has had a single panic attack may become worried about having more. So that person will tend to be more vigilant, in general, to unusual bodily sensations. This vigilance, as noted above, can set the stage for recurring attacks. Second, a person who has experienced a single attack tends to avoid the situation that brought on the attack (e.g., the threatening yoga posture). As a consequence, this person is deprived of opportunities for disconfirming his or her mistaken beliefs about panic attacks (Salkovskis 1991). There may be other mechanisms as well. Recent research places emphasis on the intolerance of uncertainty as another mechanism in the etiology and maintenance of panic disorder (Carleton et al. 2013).

Panic disorder, then, constitutes a complex, self-reproducing system. But it seems counterintuitive, as well as contrary to normal medical judgment, to say that panic attacks have functions, or that their components have functions. For example, panic attacks do not have the function of inducing hypervigilance to bodily sensations. They are prima facie dysfunctional states. I will return to this point in the conclusion.

\section{Organizational Differentiation.}

In a recent series of papers, several philosophers collaboratively produced what they call the "organizational account" of functions (Mossio et al. 2009; Saborido et al. 2011; Moreno and Mossio 2015; Mossio and Saborido 2016). This group relies heavily on the conceptual framework of general systems theory to articulate their view, but the basic 
Copyright Philosophy of Science 2017

Preprint (not copyedited or formatted)

Please use DOI when citing or quoting

outline is fairly easy to understand. Although the details and terminology vary somewhat in different presentations, I will focus on the way the theory is presented in Mossio et al. (2009). The interested reader is urged to consult Moreno and Mossio (2015) for a recent formulation.

Mossio et al. (2009) first identify a class of systems they call "self-maintaining" systems. These systems act in such a way as to promote their own continued existence. An organism is a self-maintaining system, and so are hurricanes and candle flames. They direct the flow of matter and energy in such a way as to sustain themselves. Specifically, these systems have a number of different components that depend on each another. When a component performs an activity that contributes to the maintenance of a whole, it indirectly contributes to its own continued existence. This situation - where there are a number of components that depend on one another for their continued existence - is called "closure" (following Varela 1979).

Mossio et al. $(2009,825)$ recognize that being a component of a self-maintaining system is not sufficient for having a function. If it were, then the parts of candle flames and hurricanes would have functions. So they restrict functions to components of what they call "organizationally differentiated" self-maintaining systems. In an organizationally differentiated system, we can "distinguish between different contributions to selfmaintenance made by the constitutive organization," and each component makes a "specific contribution to the conditions of existence of the whole organization" (826). Simply put, in an organizationally differentiated system, different parts do different sorts of things to maintain the system as a whole.

While this amendment can probably exclude some of the counterexamples, like candle flames, it succumbs to the panic disorder example. Panic disorder fits the description of an organizationally differentiated self-maintaining system. We can call this the "panic system." The components of the panic system are psychological states such as beliefs, desires, affects, and behavioral dispositions. One component is hypervigilance to bodily sensations. This causes the catastrophizing misinterpretation, which propels the panic attack. False beliefs constitute another component (e.g., the belief that a certain posture can cause heart attacks). These false beliefs cause avoidance behaviors, which cause more attacks. A third component is the attack itself, which reinforces the first two components. Someone might object that the panic system is not an organizationally differentiated system because I have described it in psychological terms rather than in biological terms, but I do not think that makes a difference. We can safely assume that each psychological component is realized by an underlying neural mechanism, even if these mechanisms differ somewhat in different people.

One way a proponent of the organizational account might respond is to say that functions should be restricted to the parts of organisms on the basis of the way those parts contribute to the persistence or reproduction of the organism itself, rather than to the persistence of various subsystems within the organism (such as the panic system). This would take care of the counterexample, since panic disorders typically do not help people 
Copyright Philosophy of Science 2017

Preprint (not copyedited or formatted)

Please use DOI when citing or quoting

survive. But this restriction would go against the whole point of the organizational account. The organizational account is supposed to give us a very general account of what constitutes a system, one that abstracts away from the biological details of the organism. For example, Saborido et al. $(2011,597)$ suggest that parts of ecosystems can have functions by virtue of how they maintain the whole ecosystem. So, that maneuver would not work for them.

\section{The Value Criterion.}

One final version of the organizational approach is McLaughlin's (2001). McLaughlin agrees with Wright (1973) that in order for a trait to have a function, it must have done something that contributed to its own persistence or recurrence. He also agrees with Wright that natural selection in the evolutionary sense is too narrow a basis for functions. So, he articulates a more general "feedback" criterion. In order to have a function, the trait token must have contributed either to its own recurrence or persistence (167).

McLaughlin considers a potential liberality objection against the selected effects theory. This objection was formulated by Marc Bedau (1991). Bedau states that a group of replicating clay crystals can exemplify all of the traditional ingredients of natural selection. They can undergo differential replication with something like inheritance. But clay crystals do not have functions. Bedau uses this to reject the selected effects theory (though see Garson forthcoming for a response). Bedau also concludes from this that functions involve an irreducible value element. The reason clay crystals do not have functions is that, unlike organisms, they do not have a "good" (655). Nothing can benefit clay crystals and nothing can harm them.

McLaughlin agrees with Bedau's restriction. Specifically, he holds that in order for a trait to have a function, the activity in question must benefit the system (191). Leaky hoses do not have functions because the leak does not benefit the hose. Nothing benefits the hose since the hose is not the sort of thing that has a good. Interestingly, Wright $(2013,237)$ makes a very similar move in later work. He suggests that the Boorse-type cases can be dispensed with if we restrict functions to traits that have a "virtue etiology."

Clearly, this move raises the question of what it is for a system to have a good. To my knowledge, McLaughlin does not offer any extensive analysis of this crucial notion in his book. I suspect that any careful analysis of this notion would take us far beyond the narrow confines of a naturalistic theory of function. After all, many philosophers think that what makes a view naturalistic is precisely its appeal to value-neutral predicates (e.g., Kingma 2010, 242). So, to the extent that one thinks that being naturalistic is a good desideratum for a theory of function, one should reject McLaughlin's view. Perhaps McLaughlin has some naturalistic construal of what it is for a system to have a good, one that would show why organisms have a good and clay crystals do not. It would be easier to evaluate his theory once this crucial notion is properly unpacked. 
Copyright Philosophy of Science 2017

Preprint (not copyedited or formatted)

Please use DOI when citing or quoting

I have examined three different attempts to avoid the Boorse-type liberality problem. The first two fail because they succumb to comparable liberality objections. The last fails because it is not naturalistic. I do not think that the organizational theory is entirely devoid of value. It can probably be construed as a theory of something else, such as biological autonomy, or even biological individuality. But it does not work as a theory of function.

\section{Objections and Replies.}

Here are two possible objections. First, one might ask why components of panic disorder can't have functions. After all, parts of viruses can have functions, even if they are harmful to their hosts. And many people - myself included - are willing to attribute functions to the components of tumors on the basis of how they help the tumor persist and grow. Just because something is harmful to us doesn't mean it doesn't have functions of its very own. Mechanisms of immune therapy resistance have a function for the tumor, but not for the person affected by the tumor (Garson 2013, 321).

I think this is an important objection, and I must be more cautious in exactly what I wish to say about panic disorder. I do not wish to claim that it is either logically, or nomologically, impossible for components of panic disorder to have functions. I can imagine various real-world situations that would lead me to think that the parts of panic disorder have functions. But it seems to me that merely contributing to one's own persistence, even in a complex manner, is not enough for having functions. In other words, the organizational theorists marshal the wrong sort of evidence to show that something has a function.

Consider tumors. I think the parts of tumors have bona fide biological functions. A population of cancer cells can exhibit a diverse array of "adaptive strategies" to subvert the normal barriers to unregulated somatic cell multiplication. These barriers include apoptosis and immune recognition. Tumors can also change their protein expression patterns in the course of immune therapy in such a way as to increase their resistance to such therapies (Landsberg et al 2012). As cancer researchers Gatenby and Gillies (2008, 56) recently put it, "Somatic evolution of invasive cancer can ...be viewed as a sequence of phenotypical adaptations to these barriers."

The reason tumors can generate such powerful adaptations in the course of therapy is because a population of cancer cells undergoes a selection process, somatic selection, rather than normal natural selection. This makes it a paradigm Darwinian population (Lean and Plutynski 2016; though see Germain 2012 for a skeptical view). Hence, it can exhibit the sort of adaptability that we associate with populations of organisms in the wild.

The ability of cancer cells to generate new adaptations in the face of natural and artificial growth barriers suggests that we are dealing with genuine functions. But, to my knowledge, there is no analogy whatsoever between the adaptability we find in a 
Copyright Philosophy of Science 2017

Preprint (not copyedited or formatted)

Please use DOI when citing or quoting

population of cancer cells and panic disorder. I suppose that if panic disorder were found to undergo adaptive variations that enabled it to resist the onslaught of novel therapies, then I would be inclined to think we were dealing with real functions. But the fact that it merely happens to perpetuate itself, even in a complex way, doesn't strike me as enough.

Here is a second, quite general, complaint. One might think that my main line of argumentation in this paper exhibits some deep methodological flaw. One might suspect that I am engaging in the sort of old-fashioned conceptual analysis that is now on the fringes of mainstream philosophy, and for good reasons (e.g., Stich 1996, 171-174). In this antiquated project, someone comes up with a clever analysis that is supposed to provide necessary and sufficient conditions for the application of a term like "function." Moreover, this analysis is supposed to apply to every possible world. Someone else comes up with a real or fictitious counterexample to debunk that analysis. Not only is it almost impossible to come up with such necessary and sufficient conditions, but also, people can disagree about intuitions. Here, the organizational theorists came up with a theory, I came up with a counterexample (panic disorder), and I urge, on the basis of that counterexample, that we abandon the theory. Is that a respectable way to do philosophy?

There are several complex issues that deserve to be untangled here, but there are three main points I wish to make in response. First, this complaint is simply not available to any of the organizational theorists. That is because all of them, in developing their theories, freely appeal to intuitions about systems that do not have functions, such as leaky hoses, obesity, hurricanes, candle flames, and clay crystals. So, at the very least, it would be a double standard to complain that my appealing to intuitions, for the purpose of rejecting their view, exhibits some deep methodological flaw. Second, I agree that we should be suspicious about counterexamples that rely on intuitions about bizarre, fictitious cases such as swamp-creatures (e.g., Amundson and Lauder 1994, 445). These aren't the sorts of cases that biologists or other relevant professionals have ever encountered, so we should not expect to be able to make reliable judgments about how to classify them. But panic disorder isn't a bizarre or fictitious case. It is a real-life case drawn from neuroscience and psychology that a good theory of function should deliver the right verdict on.

Third, and most important, my argument is not solely based on something as elusive as intuition. It is based on careful attention to the way that biologists and psychologists actually talk about functions. One can think that careful attention to the way that scientists use concepts in real-world scenarios is an important part of philosophy without engaging in the sort of inflated project that Stich describes (Neander 1991). Panic disorder is almost universally described as involving cognitive and/or biological dysfunctions (e.g., Ludewig et al. 2005). I am not saying that philosophers mush slavishly follow the way scientists talk. I am open to the possibility that philosophers might discover, upon reflection, that functions are quite different than what scientists think they are. But I think the best way to figure out what functions are is, first and foremost, to examine carefully how biologists think about them, that is, to identify some of the deeply entrenched assumptions that govern the way biologists and other relevant professionals 
Copyright Philosophy of Science 2017

Preprint (not copyedited or formatted)

Please use DOI when citing or quoting

attribute functions to traits. If one's theory of function completely defies those deeply entrenched assumptions, then we have a strong prima facie reason for rejecting that theory. 
Copyright Philosophy of Science 2017

Preprint (not copyedited or formatted)

Please use DOI when citing or quoting

\section{References}

American Psychiatric Association. 2013. Diagnostic and Statistical Manual of Mental Disorders: DSM-5. Washington DC: American Psychiatric Association.

Amundson, R., and G. V. Lauder. 1994. "Function without purpose: The uses of causal role function in evolutionary biology." Biology and Philosophy 9: 443-69.

Artiga, M., and M. Martínez. 2016. "The organizational account of function is an etiological account of function." Acta Biotheoretica 64: 105-17.

Bedau, M. 1991. “Can biological teleology be naturalized?” Journal of Philosophy 88: 647-55.

Boorse, C. 1976. "Wright on functions.” Philosophical Review 85: 70-86.

Christensen, W. D. and M. H. Bickhard. 2002. "The process dynamics of normative function." The Monist 85: 3-28.

Clark, D. M. 1996. "A cognitive approach to panic disorder." Behaviour Research and Therapy 24: 461-70.

Clark, D. M. 1997. "Panic Disorder and Social Phobia." In Science and Practice of Cognitive Behaviour Therapy, Ed. D. M. Clark and C. G. Fairburn, 119-53. Oxford: Oxford University Press.

Delancey, C. S. 2006. "Ontology and teleofunctions: A defense and revision of the systematic account of teleological explanation." Synthese 150: 69-98.

Garson, J. 2011. "Selected effects functions and causal role functions in the brain: The case for an etiological approach to neuroscience." Biology and Philosophy 26: $547-65$.

Garson, J. 2012. "Function, selection, and construction in the brain." Synthese 189: 45181.

Garson, J. 2013. "The functional sense of mechanism." Philosophy of Science 80: 31733.

Garson, J. 2015. The Biological Mind: A Philosophical Introduction. London: Routledge.

Garson, J. 2016. A Critical Overview of Biological Functions. Dordrecht: Springer.

Garson, J. Forthcoming. "A generalized selected effects theory of function." Philosophy of Science. 
Copyright Philosophy of Science 2017

Preprint (not copyedited or formatted)

Please use DOI when citing or quoting

Gatenby, R. A., and R. J. Gillies. 2008. "A microenvironmental model of carcinogenesis." Nature Reviews Cancer 8: 56-61.

Germain, P. 2012."Cancer cells and adaptive explanations." Biology and Philosophy 27: 785-810.

Hempel, C. G. 1965. "The logic of functional analysis." In Aspects of Scientific Explanation, ed. C. G. Hempel, 297-330. New York: Free Press.

Kingma, E. 2010. "Paracetamol, poison, and polio: Why Boorse's account of function fails to distinguish health and disease." British Journal for the Philosophy of Science 61: 241-64.

Landsberg, Jennifer, et al. 2012. "Melanomas resist t-cell therapy through inflammationinduced reversible dedifferentiation." Nature 490: 412-16.

Lean, C., and Plutynski, A. 2016. "The evolution of failure: Explaining cancer as an evolutionary process." Biology and Philosophy 31: 39-57.

Ludewig, S., et al. 2005. "Information-processing deficits and cognitive dysfunction in panic disorder." Journal of Psychiatry and Neuroscience 30: 37-43.

McLaughlin, P. 2001. What Functions Explain: Functional Explanation and SelfReproducing Systems. Cambridge: Cambridge University Press.

Millikan, R. G. 1984. Language, Thought, and Other Biological Categories. Cambridge, MA: MIT Press.

Moreno, A., and Mossio, M. 2015. Biological Autonomy: A Philosophical and Theoretical Inquiry. Dordrecht: Springer.

Mossio, M., and C. Saborido. 2016. "Functions, organization, and etiology: A reply to Artiga and Martinez." Acta Biotheoretica 64: 263-75.

Mossio, M., C. Saborido, and A. Moreno. 2009. "An organizational account for biological functions." British Journal for the Philosophy of Science 60: 813-41.

Nagel, E. 1953. "Teleological explanation and teleological systems." In Vision and Action, ed. S. Ratner, 537-58. New Brunswick, NJ: Rutgers University Press.

Nanay, B. 2010. "A modal theory of function." Journal of Philosophy 107: 412-31.

Neander, K. 1983. Abnormal Psychobiology. Dissertation, La Trobe. 
Copyright Philosophy of Science 2017

Preprint (not copyedited or formatted)

Please use DOI when citing or quoting

Neander, K. 1991. "Functions as selected effects: The conceptual analyst's defense." Philosophy of Science 58: 168-184.

Saborido, C., Mossio, M., and Moreno, A. 2011. "Biological organization and crossgeneration functions." British Journal for the Philosophy of Science 62: 583-606.

Salkovskis, P. M. 1991. "The importance of behaviour in the maintenance of anxiety and panic: A cognitive account." Behavioural and Cognitive Psychotherapy 19: 6-19.

Sarkar, S. 2005. Molecular models of life. Cambridge, MA: MIT Press.

Schlosser, G. 1998. "Self-re-production and functionality: A systems-theoretical approach to teleological explanation." Synthese 116: 303-54.

Stich, S. 1996. Deconstructing the Mind. Oxford: Oxford University Press.

Varela, F. 1979. Principles of Biological Autonomy. Elsevier: North Holland.

Weber, M. 2005. Philosophy of Experimental Biology. Cambridge: Cambridge University Press.

Wright, L. 1973. "Functions.” Philosophical Review 82: 139-68.

Wright, L. 2013. Epilogue. In Function: Selection and Mechanisms, ed. P. Huneman, 233-243. Dordrecht: Springer. 